\title{
ESTUDO DE INICIATIVAS EM DESENVOLVIMENTO SUSTENTÁVEL DE PRODUTOS EM EMPRESAS CALÇADISTAS A PARTIR DO CONCEITO BERÇO AO BERÇO
}

\author{
Jocelise Jacques de Jacques, Dra. (UFRGS); \\ Lia Buarque de Macedo Guimarães (UFRGS)
}

O impacto ambiental relacionado à exploração de recursos naturais, às emissões de carbono, mudanças climáticas, pegada ecológica e nível de desenvolvimento humano pode ser considerado um problema decorrente do fluxo linear de produção-consumo. Reconhecer a necessidade de mudança é importante, no entanto, questiona-se como fazer com que a escala de crescimento econômico e social atual comporte a co-evolução ambiental almejada. Uma forma de pensar novas possibilidades reside na concepção de produtos e sistemas produtivos que deixam a lógica linear (cradle to grave) para assumir a lógica cíclica (cradle to cradle). Projetar produtos e seus componentes para, ao final de seu uso, serem reutilizados com suas propriedades não desgastadas, como nutrientes tecnológicos no chamado metabolismo tecnológico, ou então voltarem à natureza como nutrientes biológicos e não como poluentes, através do metabolismo biológico (AYRES e SIMONIS, 1994; VAN DER RYN e COWAN, 1996; MCDONOUGH e BRAUNGART, 2002; GUIMARÃES, 2006).

Defende-se, assim, o re-projeto da produção industrial e a abrangência de usos de produtos, e aponta-se, como a próxima fronteira, o repensar de tudo que é consumido: o que é, de onde vem, para onde vai (HAWKEN, LOVINS et al., 1999). O direcionamento das iniciativas de transformação, de forma sistêmica, relaciona-se ao conceito de ecoeficácia, em que se busca alcançar o sucesso em questões ambientais, em longo prazo. Este conceito significa trabalhar nas coisas certas, em produtos e sistemas de serviços corretos, ao invés de amenizar coisas erradas (McDONOUGH e BRAUNGART, 2002). Porém, é mais simples demonstrar que a forma como interagimos com o planeta atualmente é insustentável, e menos claro quando tenta-se demonstrar como poderia ser completamente sustentável. Graedel e Klee (2002) defendem a necessidade de métricas para aferir o alcance de objetivos e metas de sustentabilidade.. Assim, sugere-se que a investigação de como se faz, inicie na análise de boas práticas incrementais que já estão postas em prática, para verificar pontos positivos e lacunas ainda não resolvidas.

Neste sentido, propõem-se uma estrutura de análise comparativa entre produtos convencionais e produtos declarados verdes. Adotando a estrutura das cinco grandes áreas previstas na certificação $C 2 C$, cujos: (1) materiais, (2) reutilização de materiais, (3) energia, (4) água e (5) responsabilidade social. Cada área é detalhada segundo critérios específicos conforme descrito na Figura 1.

Figura 01: Critérios e subcritérios de avaliação.

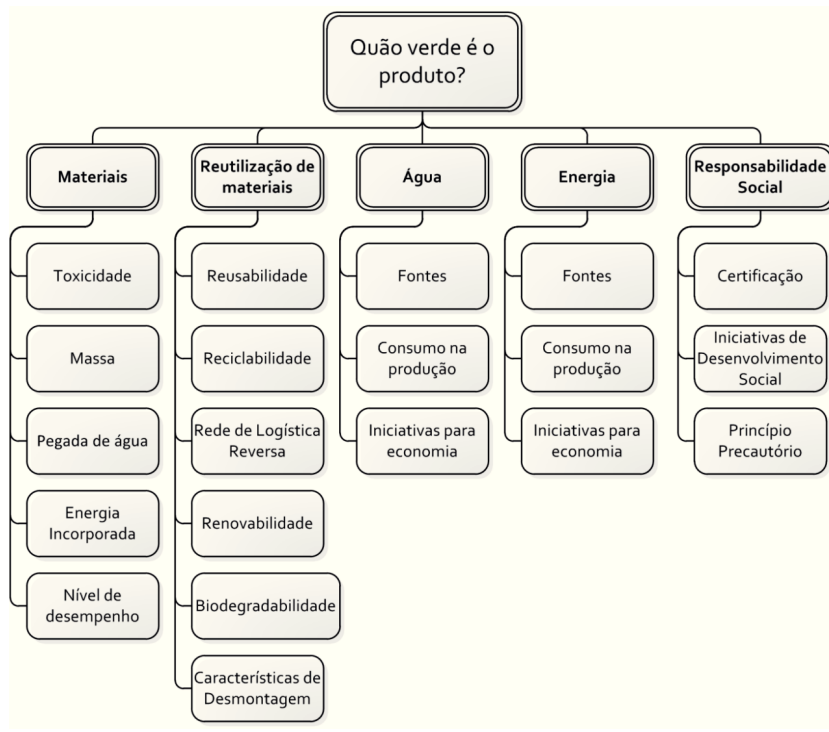

Fonte: Elaborado pelos autores

Esta forma de análise foi aplicada na análise da cadeia calçadista, visando estudar as iniciativas ambientais postas em prática até 2010, registrando como organizações que desenvolvem produtos estavam modificando suas práticas, tanto pela necessidade de atender legislações e 
exigências governamentais mais rígidas em termos ambientais, quanto para alcançar novos mercados consumidores ou manter suas parcelas já conquistadas.

A investigação sobre as iniciativas ambientais foi conduzida com base em estudos de casos exploratórios na indústria calçadista. Este setor tem características similares a vários outros, tais como alcance global, considerável impacto ambiental e econômico, centralização da manufatura e complexa cadeia produtiva e de distribuição. As iniciativas ambientais estudadas mostram que havia ênfase principalmente no projeto do produto, para enfrentar os problemas ambientais mais proeminentes, os quais se enquadram dentro das cinco principais áreas envolvidas no conceito e avaliadas na certificação berço ao berço, como toxicidade de materiais e processos produtivos, fim de ciclo de vida, consumo de água e energia e responsabilidade social. As metas e os resultados alcançados variaram de acordo com as particularidades associadas ao modelo de negócio, público alvo e nicho de mercado de cada empresa. Da mesma forma, as informações fornecidas pela empresa aos seus consumidores podem ser relacionadas ao tipo de produto e aos usuários a que se destinam.

Muitos desafios e pontos não resolvidos existem para se alcançar o conceito berço ao berço, porém, objetivos de longo prazo em relação ao metabolismo tecnológico ou biológico começam a ser discutidos com seriedade, dentro das equipes de desenvolvimento de produto. Mas para isto, necessita-se de formas de avaliar soluções de projeto desde cedo e ao longo de todo o processo de desenvolvimento de produtos, e no sentido de contribuir para que profissionais de desenvolvimento de produto possam incorporar critérios de avaliação ambiental e social no seu processo de tomada de decisão. 